\title{
Influência do pH nas características físico-químicas e sensoriais de frozen yogurt de morango
}

\section{Influence of pH on the physicochemical and sensorial characteristics of strawberry frozen yogurt}

\author{
Gustavo das Graças Pereira ${ }^{1 *}$; Leonardo Mesquita Rafael²; \\ Adriano Alvarenga Gajo ${ }^{3}$; Thaís de Melo Ramos'; Sandra Maria Pinto \\ Luiz Ronaldo de Abreu ${ }^{4}$; Jaime Vilela de Resende ${ }^{4}$
}

\begin{abstract}
Resumo
O frozen yogurt é uma sobremesa fermentada congelada que apresenta características estruturais semelhantes ao sorvete e propriedades nutricionais e sensoriais que se assemelham ao iogurte. A acidificação da mistura base por meio das bactérias lácticas pode influenciar as propriedades do frozen yogurt. Por esse motivo, o presente trabalho objetivou avaliar a influência do $\mathrm{pH}$ nas características físico-químicas e sensoriais de frozen yogurt de morango. A formulação consistiu de $6 \%$ de gordura láctea; $10 \%$ de sólidos desengordurados do leite; $11 \%$ de sacarose; $3 \%$ de xarope de milho; 0,3\% de emulsificantes e $0,5 \%$ de estabilizantes. As misturas base de frozen yogurt foram elaboradas com diferentes pontos finais de fermentação, valores de $\mathrm{pH}$ de 4,5; 5,0 e 5,5. O preparado de frutas de morango foi adicionado à mistura base fermentada em um nível de $4 \%(\mathrm{~m} / \mathrm{m})$. De acordo com os resultados, o pH da mistura base de frozen yogurt não influenciou as concentrações de proteína, gordura e cinzas, enquanto que os teores de acidez, açúcares redutores, não redutores e totais sofreram influência do $\mathrm{pH}$ em decorrência da fermentação. Avaliou-se a aceitabilidade dos frozen yogurts em relação aos atributos sabor, textura, aspecto global e acidez ideal. Observou-se que o pH influenciou a aceitação do frozen yogurt, sendo que os tratamentos com $\mathrm{pH}$ final de 5,0 e 5,5 apresentaram maior aceitabilidade para todos os atributos avaliados e acidez mais próxima à ideal. Por meio da análise de componentes principais verificou-se que as características físico-químicas teor de acidez titulável e concentração de açúcares (redutores, não redutores e totais) tiveram efeito na aceitação do produto. Em conclusão, os frozen yogurts de morango com $\mathrm{pH}$ 5,0 e 5,5 demonstraram boa aceitação sensorial e, assim, apresentam potencial de serem melhor explorados pelas indústrias de gelados comestíveis.
\end{abstract}

Palavras-chave: Frozen yogurt, pH, caracterização físico-química, aceitação sensorial

\footnotetext{
Abstract

Frozen yogurt is a frozen fermented dessert which presents structural characteristics similar to ice cream and nutritional and sensorial properties which resemble to yogurt. The acidification of ice cream mix by means of lactic bacteria can influence the properties of frozen yogurt. For that reason, the present work aimed to evaluate the influence of $\mathrm{pH}$ on the physicochemical and sensorial characteristics of strawberry frozen yogurt. The formulation consisted of $6 \%$ of milk fat, $10 \%$ of milk solids-not-fat,

1 Doutorando em Tecnologia de Alimentos, Universidade Estadual de Campinas, UNICAMP, Campinas, SP. E-mail: pereiragg@

2 Eng ${ }^{\circ}$ de Alimentos, Universidade Federal de Lavras, Lavras, MG. E-mail: leonardomesquitarafael@gmail.com

3 Doutorando(a) em Ciência dos Alimentos, Universidade Federal de Lavras, UFLA, Lavras, MG. E-mail: gajoadriano@yahoo. com.br; thaisramos85@yahoo.com.br

4 Profs. do Dept ${ }^{\circ}$. de Ciência dos Alimentos, UFLA, Lavras, MG. E-mail: sandra@ufla.br; lrabreu@ufla.br; jvresende@ufla.br Autor para correspondência ymail.com 
$11 \%$ of sucrose, $3 \%$ of corn syrup, $0.3 \%$ of emulsifiers and $0.5 \%$ of stabilizers. The frozen yogurt mixes were made with different fermentation endpoints, $\mathrm{pH}$ values of 4.5, 5.0 and 5.5. The strawberry fruit mixture was added to the fermented frozen yogurt mix at a level of $4 \%(w / w)$. According to the results, the $\mathrm{pH}$ of the frozen yogurt mix did not influence the concentrations of protein, fat and ash whereas the contents of acidity, reducing, non-reducing and total sugars underwent influence of $\mathrm{pH}$ due to fermentation. The acceptability of frozen yogurt in relation to the attributes flavor, texture, overall acceptance and ideal acidity was evaluated. It was found that $\mathrm{pH}$ influenced the acceptance of frozen yogurt; the treatments with final $\mathrm{pH}$ of 5.0 and 5.5 presented higher acceptability for all the treatments evaluated and acidity close to the ideal. By means of the principal component analysis, it was found that the physicochemical characteristics acidity content and sugar concentration (reducing, non-reducing and total) had effect on the acceptance of the product. In conclusion, the strawberry frozen yogurts with pH 5.0 and 5.5 demonstrated good sensorial acceptance and thus, presented potential of being better explored by the ice cream industries.

Key words: Frozen yogurt, pH, physicochemical characterization, sensorial acceptance

\section{Introdução}

O frozen yogurt é uma sobremesa láctea fermentada e congelada que combina as características físicas do sorvete com as propriedades sensoriais e nutricionais do leite fermentado. O frozen yogurt pode ser considerado uma alternativa saudável ao sorvete para as pessoas que sofrem com obesidade, doenças cardiovasculares e intolerância à lactose, em decorrência do seu baixo conteúdo de gordura (o percentual de gordura em um sorvete de iogurte padrão varia de 3,5 a $6 \%$ ) e reduzido teor de lactose, o qual depende estritamente do tipo e duração da fermentação (MARSHALL; GOFF; HARTEL, 2003; TAMIME; ROBINSON, 2007). Além disso, ofrozen yogurt apresenta maior vida de prateleira quando comparado ao iogurte (LOPEZ; MEDINA; JORDANO, 1998; CURIA et al., 2005; SALVADOR et al., 2005).

Frozen yogurts podem ser produzidos de acordo com três técnicas básicas: (i) método da acidificação direta, (ii) método da acidificação indireta e (iii) método da adição. Quando a técnica de acidificação direta é utilizada, uma mistura base de sorvete é inoculada com uma cultura láctica starter (Streptococcus thermophilus e Lactobacillus delbrueckii ssp. bulgaricus na razão 1:1), incubada de 12 a 18 horas, resfriada, batida, congelada e armazenada sob temperatura de congelamento. A acidificação indireta envolve a combinação entre mistura base de sorvete e iogurte (iogurte natural ou leite fermentado), em proporções que variam de $5 \%$ a $70 \%$ dependendo da proporção de iogurte desejada, características de batimento, congelamento e armazenamento. O método da adição referese a incorporação da bactéria ácido-láctica antes do congelamento sem nenhuma fermentação da mistura (SOUKOULIS; TZIA, 2008).

Os ingredientes comumente utilizados na produção de sorvete também são convenientes para a elaboração de frozen yogurt, incluindo hidrocolóides (estabilizantes), emulsificantes, açúcares, sólidos não gordurosos do leite, gordura e substitutos de gordura (SOUKOULIS; TZIA, 2008; GÜVEN; KARACA, 2002). Da mesma forma, o processo de elaboração do frozen yogurt é semelhante ao do sorvete, com exceção da etapa de fermentação. Assim, o frozen yogurt pode ser produzido em uma planta tradicional de sorvete com praticamente nenhuma alteração em sua estrutura.

$\mathrm{Na}$ produção de frozen yogurt normalmente emprega-se uma cultura mista de Lactobacillus delbrueckii ssp. bulgaricus e Streptococcus thermophilus. Essas bactérias lácticas estimulamse mutuamente, complementando o crescimento uma da outra. No início da fermentação, o pH do leite favorece o desenvolvimento do Streptococcus thermophilus. Com o aumento da acidificação, ou seja, do teor de ácido láctico a partir da lactose, crescem os Lactobacillus delbrueckii ssp. bulgaricus. Estes são proteolíticos, obtêm 
aminoácidos a partir da caseína (glicina, histidina, valina) e ativam o crescimento dos estreptococos que, por sua vez, estimulam o crescimento dos lactobacilos, com a produção de ácido fórmico e gás carbônico (RODAS et al., 2001).

Em decorrência da fermentação de parte dos açúcares presentes na mistura base do frozen yogurt por meio da ação da cultura láctica, ocorre uma acidificação do mesmo, originando características sensoriais similares as do leite fermentado. Essa acidificação pode influenciar diretamente as características físico-químicas e sensoriais do frozen yogurt. Até o momento, não existe nenhuma regulamentação que estabeleça uma faixa de $\mathrm{pH}$ ou acidez titulável (expressa em g/100g ácido láctico) recomendável para esse produto. De acordo com Tamime e Robinson (2007), a faixa de $\mathrm{pH}$ comumente encontrada em frozen yogurts comercializados nos Estados Unidos varia de 4,37 a 5,70 .

Sendo assim, o presente trabalho objetivou investigar a influência de diferentes valores de $\mathrm{pH}$ da mistura base nas características físico-químicas e sensoriais de frozen yogurt de morango.

\section{Material e Métodos}

\section{Formulação do frozen yogurt de morango}

A mistura base de frozen yogurt continha $6 \%$ de gordura láctea (creme de leite e leite integral, Laticínios Verde Campo, Lavras, MG, Brasil); 10 $\%$ de sólidos desengordurados do leite (leite em pó desnatado instantâneo, Nestlé, São Paulo, SP, Brasil; creme de leite e leite integral); $11 \%$ de sacarose (Companhia União, São Paulo, SP, Brasil); 3 \% de xarope de milho 38 D.E (Mor-Rex 1940®, Corn Products Brasil, São Paulo, SP, Brasil); 0,3 \% de emulsificantes (Emustab®, Duas Rodas Industrial, Jaraguá do Sul, SC, Brasil) e 0,5\% de estabilizantes (Liga Neutra ${ }^{\circledR}$, Duas Rodas Industrial). A cultura láctica starter contendo Lactobacillus delbrueckii ssp. bulgaricus e Streptococcus thermophilus
(Centro Sperimentalle Del Latte, Zelo Buon Perisco, LO, Itália) foi inoculada à mistura base em um nível de $0,2 \%$ em relação ao volume da mistura base, enquanto o preparado de frutas a base de morango (Borsato, Farroupilha, RS, Brasil) foi adicionado à mistura base em um nível de $4 \%$ em relação ao peso da mistura base. O preparado de frutas consistia em uma polpa de morango em pedaços, especialmente designada para a elaboração de produtos lácteos e que confere características de sabor, aroma e coloração.

A Tabela 1 representa a formulação da mistura base utilizada na produção do frozen yogurt.

Tabela 1. Formulação da mistura base de frozen yogurt.

\begin{tabular}{cc}
\hline Ingredientes & Peso Total $(\mathbf{K g})$ \\
\hline Creme de leite & 1,108 \\
Leite integral & 11,908 \\
Leite em pó desnatado & 0,616 \\
Sacarose & 1,760 \\
Xarope de milho & 0,480 \\
Estabilizante & 0,080 \\
Emulsificante & 0,048 \\
\hline Total & $\mathbf{1 6 , 0 0 0}$ \\
\hline
\end{tabular}

Fonte: Elaboração dos autores.

\section{Produção do frozen yogurt de morango}

A fabricação dos tratamentos de frozen yogurt foi realizada de acordo com os métodos propostos por Davidson et al. (2000) e Fávaro-Trindade et al. (2006) com algumas modificações (Figura 1).

Os ingredientes, com exceção do emulsificante, foram dispersos, sob agitação (3500 rpm), no leite previamente aquecido a $50^{\circ} \mathrm{C}$ com o auxílio de um liquidificador industrial (Refrigas, Bauru, SP, Brasil). Essa dispersão dos ingredientes foi, então, pasteurizada a $75^{\circ} \mathrm{C} / 15$ minutos, resfriada a $4^{\circ} \mathrm{C}$ (o emulsificante foi adicionado após o resfriamento) e mantida nessa temperatura por 24 horas para ser maturada. Após a maturação, obteve-se a mistura base, que foi reaquecida a $40^{\circ} \mathrm{C}$ para a inoculação da cultura láctica starter e incubada nesta temperatura 
até o estabelecimento do ponto final de fermentação, literatura, que variam de 4,7 a 6,7 (SCHMIDT; designado em valores de $\mathrm{pH}$ de 4,5; 5,0 e 5,5. A KIM; JEON, 1997; ORDONEZ; JEON; ROBERTS, faixa do ponto final de fermentação foi estabelecida 2000; GONÇALVES; EBERLE, 2008; KIM et al., baseada em valores comumente encontrados na 2009).

Figura 1. Fluxograma de produção do frozen yogurt de morango.

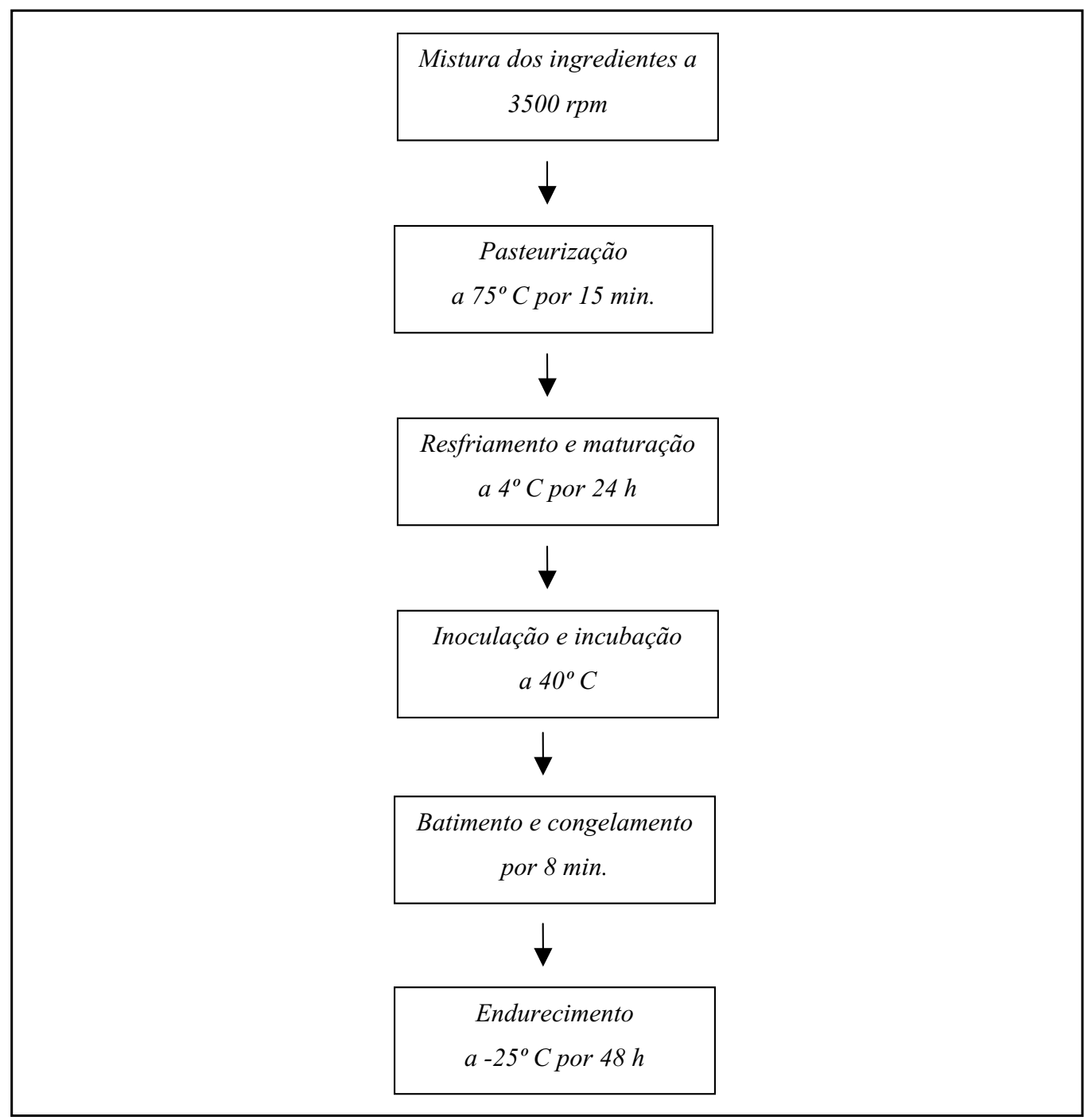

Fonte: Elaboração dos autores.

A mistura base fermentada foi resfriada a $4^{\circ}$ C para a adição do preparado de frutas a base de morango. Todos os tratamentos foram submetidos às mesmas condições de congelamento, que ocorreu em uma produtora de sorvetes descontínua horizontal (Refrigás, Bauru, SP, Brasil), com tempo de batimento de 8 minutos e overrun entre 30 e 40 $\%$. O frozen yogurt de morango foi acondicionado em embalagens apropriadas e imediatamente conduzido a uma câmara de congelamento a $-25^{\circ}$ $\mathrm{C}$, em que permaneceu nessa temperatura por 48 horas para completar a fase de endurecimento. 
Portanto, os três tratamentos de frozen yogurt foram formulados com pontos finais de fermentação designados em $\mathrm{pH} 4,5 ; 5,0$ e 5,5; descritos no texto como frozen yogurt com $\mathrm{pH} 4,5$; frozen yogurt com $\mathrm{pH} 5,0$ e frozen yogurt com $\mathrm{pH} 5,5$; respectivamente. Foram elaboradas 5 repetições de cada tratamento.

Avaliação fisico-química da mistura base de frozen yogurt de morango

Aacidez titulável foi determinada por titulometria com solução de $\mathrm{NaOH}$ 0,1 N (AOAC, 2000). O teor proteína bruta foi obtido pela determinação do teor de nitrogênio total por destilação em aparelho MicroKjedahl (AOAC, 2000), usando o fator de conversão 6,38. A concentração de gordura foi determinada pelo método de Rose-Gottlieb segundo metodologia do Instituto Adolfo Lutz (2008). A fração das cinzas foi obtida gravimetricamente, avaliando-se a perda de peso do material submetido ao aquecimento a $550^{\circ} \mathrm{C}$ em mufla (AOAC, 2000). $\mathrm{O}$ conteúdo de açúcares totais e redutores foram determinados por espectrofotometria, de acordo com o método de Somogy adaptado por Nelson (AOAC, 2000), enquanto o de açúcares não redutores foram calculados pela Equação 1 .

Açúcares não redutores $=($ Açúcares totais - Açúcares redutores $) \times 10,95$ Equação 1

Todas as avaliações físico-químicas foram realizadas com amostras de mistura base fermentadas adicionadas do preparado de frutas a base de morango $(4 \%, \mathrm{~m} / \mathrm{m})$.

\section{Avaliação sensorial do frozen yogurt de morango}

A avaliação da aceitação sensorial dos tratamentos de frozen yogurt de morango foi realizada com a participação de 50 provadores não treinados. Os três tratamentos (frozen yogurt com $\mathrm{pH}$
4,5; frozen yogurt com $\mathrm{pH}$ 5,0 e frozen yogurt com $\mathrm{pH} 5,5)$ foram apresentados em copos plásticos de $50 \mathrm{~mL}$, codificados com números aleatórios de três dígitos, sendo cada amostra constituída por cerca de $30 \mathrm{~g}$ de frozen yogurt com temperatura entre $-8{ }^{\circ} \mathrm{C}$ e $-10{ }^{\circ} \mathrm{C}$ (KEMP; HOLLOWOOD; HORT, 2009; STONE; SIDEL, 2004). A análise sensorial foi conduzida em cabines individuais, sob luz branca equivalente à do dia. Os tratamentos foram avaliados quanto aos atributos sabor, textura e aspecto global utilizando escala hedônica estruturada mista de nove pontos ( 1 = desgostei extremamente, $5=$ nem gostei/nem desgostei e 9 = gostei extremamente), segundo Meilgaard, Civille e Carr (2007). Também foi avaliada a acidez ideal dos tratamentos de frozen yogurt usando a escala do ideal de nove categorias $(-4=$ sabor extremamente menos ácido que o ideal, $0=$ acidez ideal e $+4=$ sabor extremamente mais ácido que o ideal), conforme método de Stone e Sidel (2004).

Os testes sensoriais seguiram um delineamento experimental em blocos completos casualizados, onde cada provador constituiu um bloco.

\section{Análise estatística}

Os resultados das análises físico-químicas e sensoriais foram submetidos à análise de variância (ANOVA) e as diferenças das médias comparadas por teste de Tukey ao nível de $5 \%$ de significância. Para os resultados de acidez ideal foi construído um histograma de distribuição percentual referente ás categorias. Procedeu-se também a análise de agrupamentos hierárquicos (HCA) para avaliar a similaridade entre os tratamentos e a análise de componentes principais (PCA) com intuito de verificar como as características físico-químicas influenciavam na aceitação sensorial. Os ensaios estatísticos foram conduzidos no software $\mathrm{R}$ ( $\mathrm{R}$ DEVELOPMENT CORE TEAM, Viena, Áustria, 2007). 


\section{Resultados e Discussão}

Caracterização físico-química da mistura base de frozen yogurt de morango

Os resultados referentes às análises físicoquímicas dos diferentes tratamentos de mistura base de frozen yogurt estão apresentados na Tabela 2.
As concentrações de proteína, gordura e cinzas da mistura base de frozen yogurt não foram influenciadas $(\mathrm{P}>0,05)$ pelo $\mathrm{pH}$ final de fermentação. Por outro lado, os teores de acidez titulável e de açúcares (totais, redutores e não redutores) apresentaram diferença $(\mathrm{P}<0,05)$ entre os tratamentos.

Tabela 2. Médias (g.100 $\mathrm{g}^{-1}$ ) e desvios-padrão dos parâmetros físico-químicos dos tratamentos de mistura base de frozen yogurt de morango.

\begin{tabular}{lccc}
\hline & \multicolumn{2}{c}{ Tratamento } & \\
Características & $\mathbf{p H ~ 4 , 5}$ & $\mathbf{p H ~ 5 , 0}$ & $\mathbf{p H ~ 5 , 5}$ \\
\hline Acidez titulável & $0,78 \pm 0,02 \mathrm{a}$ & $0,61 \pm 0,01 \mathrm{~b}$ & $0,51 \pm 0,02 \mathrm{c}$ \\
Proteína bruta & $3,82 \pm 0,03 \mathrm{a}$ & $3,77 \pm 0,06 \mathrm{a}$ & $3,78 \pm 0,06 \mathrm{a}$ \\
Gordura & $6,00 \pm 0,20 \mathrm{a}$ & $6,06 \pm 0,19 \mathrm{a}$ & $6,04 \pm 0,23 \mathrm{a}$ \\
Cinzas & $0,87 \pm 0,01 \mathrm{a}$ & $0,86 \pm 0,01 \mathrm{a}$ & $0,87 \pm 0,01 \mathrm{a}$ \\
Açúcares redutores & $3,80 \pm 0,72 \mathrm{c}$ & $4,17 \pm 0,03 \mathrm{~b}$ & $4,38 \pm 0,04 \mathrm{a}$ \\
Açúcares não redutores & $10,26 \pm 0,06 \mathrm{~b}$ & $10,72 \pm 0,05 \mathrm{a}$ & $10,80 \pm 0,08 \mathrm{a}$ \\
Açúcares totais & $14,61 \pm 0,12 \mathrm{c}$ & $15,45 \pm 0,07 \mathrm{~b}$ & $15,74 \pm 0,09 \mathrm{a}$ \\
\hline
\end{tabular}

Os valores correspondem a media de 5 repetições com estimativa do desvio padrão. Médias na mesma linha que possuem letras distintas diferem significativamente entre si pelo teste de Tukey $(\mathrm{P}<0,05)$.

Fonte: Elaboração dos autores.

O teor de acidez titulável da mistura base de frozen yogurt variou de 0,51 a $0,78 \%$, sendo observada diferença significativa entre todos os tratamentos $(\mathrm{P}<0,05)$. De maneira geral, quanto maior a acidez titulável encontrada em um produto lácteo fermentado, menor será o valor de $\mathrm{pH}$ e o teor de lactose desta amostra, em decorrência da produção de ácido láctico por ação de bactérias fermentativas (TRAMONTINA; RICHARDS; SILVA, 2001). A acidez obtida neste trabalho está situada dentro da faixa encontrada por Tieszen e Baer (1989), que encontraram acidez titulável para mistura base de frozen yogurt variando de 0,37 a $0,87 \%$. Na legislação nacional, até o presente momento, não existe nenhuma regulamentação que estabelece o nível mínimo de acidez para mistura base de frozen yogurt. De acordo com Davidson et al. (2000), as indústrias norte-americanas procuram atingir uma acidez titulável mínima de 0,30 \% para esse produto.
A similaridade dos resultados observados para as concentrações de proteína, gordura e cinzas em diferentes valores de $\mathrm{pH}$ da mistura base de frozen yogurt deve-se ao fato de que todos os tratamentos apresentaram a mesma formulação. Durante a fermentação, a proteína, a gordura e a lactose presentes nos compostos lácteos sofrem hidrólise parcial (RODAS et al., 2001). No entanto, somente a lactose é convertida em ácido láctico. Assim, apesar da acidificação da mistura base de frozen yogurt, as concentrações dos constituintes, com exceção dos açúcares, não diferiram entre os diferentes valores de $\mathrm{pH}(\mathrm{P}>0,05)$.

Corte (2008) e Andrade et al. (2004) obtiveram concentrações de proteína $(3,18$ a 3,69 \% e 2,63 a $2,64 \%$, respectivamente) inferiores as observadas neste trabalho (3,77 a 3,82 \%). No entanto, o nível de proteína em mistura base de frozen yogurt depende da fração de sólidos desengordurados do leite presente na formulação, que é representado, principalmente, pelo leite em pó desnatado. 
O teor de gordura comumente encontrado em misturas base de frozen yogurt comercializados nos Estados Unidos varia de 1,7 a 5,3 \% (TAMIME; ROBINSON, 2007). A concentração deste constituinte obtida neste trabalho $(6,00$ a $6,06 \%)$ foi ligeiramente superior em função da maior quantidade de gordura láctea adicionada à formulação.

A concentração de cinzas variou de 0,86 a 0,87 $\%(\mathrm{P}>0,05)$ e se assemelha com o teor de cinzas verificado por Tamime e Robinson (2007) em misturas base de frozen yogurt, cujo percentual estava entre 0,8 a $1,1 \%$. Por outro lado, Corte (2008) obteve resultados inferiores que variavam de 0,48 a $0,58 \%$. A concentração de cinzas em mistura base de frozen yogurt está diretamente relacionada à fração de sólidos desengordurados do leite presente na formulação.

O pH final de fermentação influenciou a concentração de açúcares da mistura base de frozen yogurt.

$\mathrm{O}$ teor de açúcares redutores variou de 3,80 a 4,38\% e apresentou diferença $(\mathrm{P}<0,05)$ entre os tratamentos. As bactérias ácido-lácticas obtêm energia para a realização de suas atividades vitais através da fermentação de carboidratos (VARGHESE; MISHRA, 2008). Portanto, em função do processo fermentativo, ocorreu uma diminuição na concentração de açúcares redutores à medida que se reduziu o $\mathrm{pH}$ final da mistura base de frozen yogurt.

O conteúdo de açúcares não redutores presente na mistura base de frozen yogurt é, basicamente, representado pela sacarose, adicionada na proporção de $11 \%$ na formulação do produto. A partir do processo de fermentação observou-se um decréscimo na concentração deste constituinte conforme diminuía-se o valor de $\mathrm{pH}$ (Tabela 2), sendo que as amostras de mistura base de frozen yogurt com $\mathrm{pH}$ 5,5 e 5,0 não demonstraram diferença entre si ( $\mathrm{P}>$ $0,05)$, porém diferiram da amostra com $\mathrm{pH} 4,5(\mathrm{P}<$ $0,05)$. A redução no teor de açúcares não redutores pode ser explicada pela sua inversão em D-glicose e D-frutose em decorrência do tratamento térmico e do aumento da acidez, fatores que contribuem para este fenômeno químico (RODRIGUES et al., 2000). Em condições normais, o aumento da taxa de inversão da sacarose promove a redução na concentração deste constituinte e a elevação no teor de açúcares redutores (DAMIANI et al., 2009). No entanto, no presente trabalho, os açúcares redutores diminuíram em função do processo de acidificação.

Para os açúcares totais, a concentração obtida variou de 14,61 a $15,74 \%(\mathrm{P}<0,05)$. Verificou-se um decréscimo na concentração de açúcares totais à medida que se reduziu o $\mathrm{pH}$ da mistura base de frozen yogurt. Esse comportamento é decorrente da redução dos teores de açúcares redutores e não redutores, conforme mencionado nos parágrafos anteriores.

\section{Avaliação sensorial do frozen yogurt de morango}

Os dados referentes às notas do teste de aceitabilidade do frozen yogurt encontram-se na Tabela 3.

Tabela 3. Médias de aceitação dos atributos sensoriais e da acidez ideal dos tratamentos de frozen yogurt de morango.

\begin{tabular}{lccc}
\hline & & Tratamento & \\
Atributo & $\mathrm{pH} \mathrm{4,5}$ & $\mathrm{pH} \mathrm{5,0}$ & $\mathrm{pH} \mathrm{5,5}$ \\
\hline Sabor $^{1}$ & $6,48 \mathrm{~b}$ & $7,46 \mathrm{a}$ & $7,84 \mathrm{a}$ \\
Textura $^{1}$ & $6,60 \mathrm{~b}$ & $7,54 \mathrm{a}$ & $7,80 \mathrm{a}$ \\
Aspecto Global $^{1}$ & $6,70 \mathrm{~b}$ & $7,48 \mathrm{a}$ & $7,76 \mathrm{a}$ \\
Acidez ideal $^{2}$ & $1,38 \mathrm{a}$ & $0,26 \mathrm{~b}$ & $-0,25 \mathrm{c}$ \\
\hline
\end{tabular}

Médias na mesma linha que possuem letras distintas diferem significativamente entre si pelo teste de Tukey $(\mathrm{P}<0,05)$. ${ }^{1}$ Escala hedônica estruturada mista de nove pontos $(1=$ desgostei extremamente, $5=$ nem gostei/nem desgostei e $9=$ gostei extremamente $)$. ${ }^{2}$ Escala do ideal de nove categorias $(-4=$ sabor extremamente menos ácido que o ideal, $0=$ acidez ideal e $+4=$ sabor extremamente mais ácido que o ideal).

Fonte: Elaboração dos autores. 
As amostras dos diferentes tratamentos obtiveram boa aceitação, uma vez que todos os atributos avaliados (sabor, textura e aspecto global) apresentaram notas médias superior a 6 (gostei ligeiramente).

Para o atributo sabor, os tratamentos de frozen yogurt com $\mathrm{pH}$ 5,0 e 5,5 apresentaram maior aceitação $(\mathrm{P}<0,05)$. Esse resultado indica uma menor apreciação, por parte dos consumidores, do frozen yogurt com menor valor de $\mathrm{pH}(4,5)$. A atividade das culturas lácticas causa mudanças químicas específicas, liberando compostos voláteis com grupamento carbonil, como ácido láctico e acético, acetaldeído, cetonas e diacetil. A intensidade com as quais esses compostos são formados é responsável pela percepção de sabor e aroma do frozen yogurt (ALVES et al., 2009).

No presente trabalho, o valor de $\mathrm{pH} \mathrm{5,0}$ foi determinado como o limite mínimo para a obtenção de um produto com boa aceitação em relação ao sabor. Resultado semelhante foi obtido por Guner et al. (2007), onde frozen yogurts com valores de $\mathrm{pH}$ de até 5,25 apresentaram maiores escores para o sabor. Por outro lado, Hekmat e McMahon (1992) verificaram que sorvete probiótico com $\mathrm{pH}$ 5,5 foi melhor aceito em termos de sabor quando comparado ao de pH 5,0. Essa diferença de aceitação entre os trabalhos pode ser explicada pela formulação e cultura láctica utilizadas.
Os tratamentos de frozen yogurt com $\mathrm{pH} 5,0 \mathrm{e}$ 5,5 apresentaram maior aceitabilidade $(\mathrm{P}<0,05)$ em relação a textura. Os açúcares, um dos principais componentes do sorvete, além de aumentar a aceitação do produto, aprimorando o sabor e aroma, apresentam outras funções como aumentar a viscosidade e reduzir o ponto de congelamento (SOLER; VEIGA, 2001). O tratamento com pH 4,5 demonstrou menor aceitação por apresentar maior quantidade de água na forma congelada, uma vez que a concentração de açúcares nesse tratamento foi inferior (Tabela 2), em função do maior grau de transformação de parte do açúcar em ácido láctico. Portanto, uma maior quantidade de água congelada no produto final pode conferir uma textura mais arenosa.

Em relação ao aspecto global dos frozen yogurts, os tratamentos com pH 5,0 e 5,5 apresentaram maior aceitação $(\mathrm{P}<0,05)$, indicando, assim, uma dependência em relação aos atributos sabor e textura.

Quanto à acidez ideal, observa-se na Tabela 3 que houve diferença estatística $(\mathrm{P}<0,05)$ entre os tratamentos analisados, sendo que os frozen yogurts com pH 5,0 e 5,5 apresentaram notas médias próximas a 0 , mostrando, assim, acidez mais próxima ao ideal. Os resultados são complementados pela Figura 2 que ilustra a distribuição de respostas para os diferentes tratamentos.

Figura 2. Distribuição das respostas de acidez ideal para o frozen yogurt de morango.

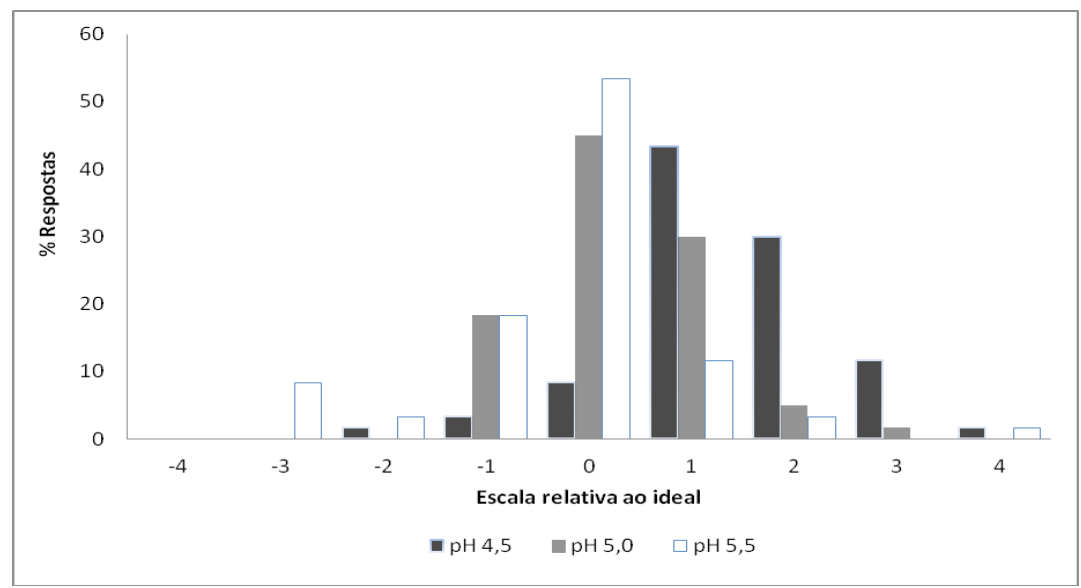

Fonte: Elaboração dos autores. 
De acordo com a Figura 2, pode-se observar que os tratamentos de frozen yogurt com $\mathrm{pH}$ 5,0 e 5,5 receberam maior porcentagem de notas 0 por parte dos consumidores, indicando uma maior aceitação desses produtos. Por outro lado o frozen yogurt com $\mathrm{pH} 4,5$ apresentou aproximadamente $87 \%$ das respostas como acima do ideal de acidez. Esse resultado indica que os consumidores preferem amostras com maior $\mathrm{pH}$ final de fermentação. Resultado semelhante foi relatado por Guinard et. al.
(1994) ao avaliar o efeito da acidez e concentração de açúcar na aceitabilidade de frozen yogurt.

Por meio da análise de agrupamento hierárquico (HCA) obteve-se um dendograma (Figura 3) para os diferentes tratamentos de frozen yogurt, onde observou-se um agrupamento entre os tratamentos com $\mathrm{pH}$ 5,0 e 5,5; evidenciando uma similaridade entre os mesmos em relação a aceitação sensorial do frozen yogurt. Esse resultado corrobora com aqueles obtidos na Tabela 3 e na Figura 2.

Figura 3. Dendograma referente aos tratamentos de frozen yogurt de morango.

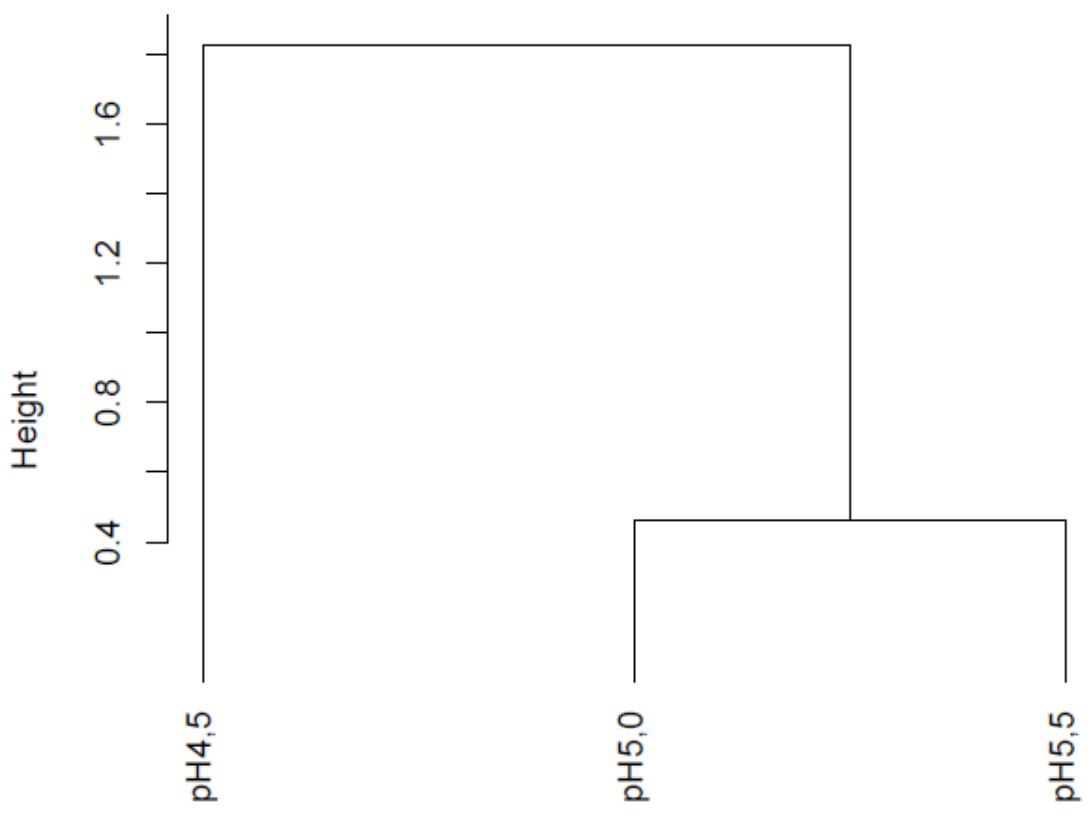

Fonte: Elaboração dos autores.

Análise de componentes principais (PCA)

Com o intuito de observar-se a influência dos parâmetros físico-químicos da mistura base na aceitação do frozen yogurt, submeteu-se os dados experimentais à análise multivariada de componentes principais.

A PCA mostrou que com a primeira e a segunda componentes principais (PC1 e PC2) foi possível explicar $100 \%$ da variância total dos dados, sendo $99,8 \%$ referente a PC1.
A análise do gráfico de loadings (Figura 4) demonstrou que os atributos sensoriais sabor e textura foram influenciados pelas características físico-químicas concentração de açúcares totais, concentração de açúcares redutores e concentração de açúcares não redutores na mistura base, sobretudo pela concentração de açúcares totais. $\mathrm{Ou}$ seja, maiores concentrações de açúcares na mistura base acarretam em uma maior aceitação sensorial para os atributos sabor e textura do frozen yogurt. Já o teor de acidez titulável se encontrou em posição 
oposta, tanto na PC1 quanto na PC2, em relação ao atributo sabor, indicando que maiores teores de acidez titulável na mistura base propiciam menores escores de aceitação para o sabor do frozen yogurt.

No entanto, conforme visto na Tabela 3, os tratamentos com pH 5,0 e 5,5 obtiveram a mesma aceitação para todos os atributos avaliados $(\mathrm{P}>$ $0,05)$, o que indica que variação das características físico-químicas para estes tratamentos não influencia em termos sensoriais.

A aceitação global mais uma vez se mostrou altamente dependente dos atributos sabor e textura, assim com havia sido observado na Tabela 3.

Figura 4. Gráfico bidimensional PC1 vs PC2 dos loadings para os atributos físico-químicos e sensoriais de frozen yogurt de morango. Abreviaturas: AT: acidez titulável, PB: proteína bruta, GR: gordura, CI: cinzas, AcR: açúcares redutores, AcNR: açúcares não redutores, AcT: açúcares totais, SB: sabor, TX: Textura, AG: aceitação global.

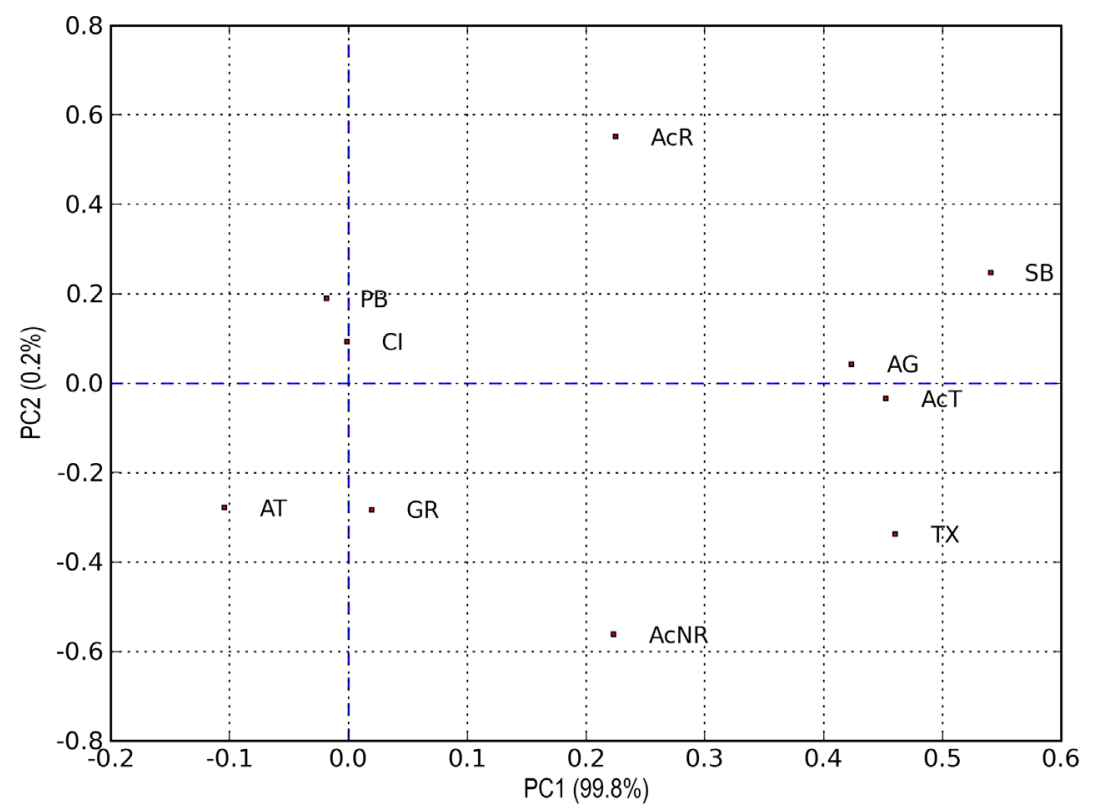

Fonte: Elaboração dos autores.

As características físico-químicas concentração de proteína, concentração de gordura e concentração de cinzas encontraram-se distribuídas próximas uma das outras. Esses resultados acrescidos daqueles obtidos na Tabela 2 ratificaram que essas características físico-químicas não influenciaram na aceitação sensorial do frozen yogurt.

Vale ressaltar que os constituintes gordura e proteína apresentam um efeito marcante na qualidade de gelados comestíveis, tanto nos aspectos sensoriais quanto estruturais. No entanto, no presente trabalho não se observou uma influência desses constituintes na aceitação dos frozen yogurts porque suas concentrações foram significativamente iguais $(\mathrm{P}<0,05)$ entre os distintos tratamentos.

\section{Conclusão}

$\mathrm{O} \mathrm{pH}$ da mistura base de frozen yogurt de morango influenciou o teor de acidez titulável e as concentrações de açúcares totais, redutores e não redutores. Esses atributos físico-químicos também 
apresentaram efeito direto na aceitação sensorial do frozen yogurt. Por outro lado, os teores de proteína, gordura e cinzas não foram influenciados pelo $\mathrm{pH}$ final da mistura base e não demonstraram efeito sobre a aceitação do frozen yogurt.

Os frozen yogurts de morango com $\mathrm{pH}$ final de 5,0 e 5,5 apresentaram maior aceitação para todos os atributos avaliados e também apresentaram acidez mais próxima à ideal.

Assim, o frozen yogurt desponta como uma alternativa de produto para a indústria nacional de gelados comestíveis, tanto pela suas marcantes características sensoriais quanto pela sua viabilidade tecnológica, uma vez que o mesmo pode ser produzido em uma planta tradicional de sorvete com praticamente nenhuma alteração em sua estrutura.

\section{Referências}

ALVES, L. L.; RICHARDS, N. S. P. S.; BECKER, L. V.; ANDRADE, D. F.; MILANI, L. I. G.; REZER, A. P. S.; SCIPIONI, G. C. Aceitação sensorial e caracterização de frozen yogurt de leite de cabra com adição de cultura probiótica e prebiótico. Ciência Rural, Santa Maria, v. 39, n. 9, p. 2595-2600, 2009.

ANDRADE, V. T.; BRANDÃO, S. C. C. B.; SARAIVA, C. B.; LEITE, M. O. Desenvolvimento de sorvete com prebiótico e probiótico. In: CONGRESSO NACIONAL DE LATICÍNIOS, 21., 2004, Juiz de Fora. Anais... Juiz de Fora, jul. 2004. p. 122-126.

ASSOCIATION OF OFFICIAL ANALYTICAL CHEMISTS - AOAC. Official methods of analysis of the association of the official analytical chemists. 17. ed. Arlington: AOAC, 2000. $2200 \mathrm{p}$.

CORTE, F. F. D. Desenvolvimento de frozen yogurt com propriedades funcionais. 2008. Dissertação (Mestrado em Ciência e Tecnologia dos Alimentos) - Departamento de Tecnologia e Ciência dos Alimentos. Universidade Federal de Santa Maria, Santa Maria.

CURIA, A.; AGUERRIDO, M.; LANGOHR, K.; HOUGH, G. Survival analysis applied to sensory shelf life of yogurts - I: Argentine formulations. Journal of Food Science, Chicago, v. 70, n. 7, p. 442-445, 2005.

DAMIANI, C.; VILAS BOAS, E. V. B.; SOARES JUNIOR, M. S.; CALIARI, M.; PAULA, M. L.; ASQUIERI, E. R. Avaliação química de geléias de manga formuladas com diferentes níveis de cascas em substituição à polpa. Ciência e Agrotecnologia, Lavras, v. 33, n. 1, p. 177-184, 2009.

DAVIDSON, R. H.; DUNCAN, S. E.; HACKNEY, C. R.; EIGEL, W. N.; BOLING, J. W. Probiotic culture survival and implications in fermented frozen yogurt characteristics. Journal of Dairy Science, Champaign, v. 83, n. 4, p. 666-673, 2000.

FÁVARO-TRINDADE， C. S.; BERNARDI, S.; BODINI, R. B.; BALIEIRO, J. C. C.; ALMEIDA, E. Sensory acceptability and stability of probiotic microorganisms and vitamin $\mathrm{C}$ in fermented acerola (Malpighia emarginata DC.) ice cream. Journal of Food Science, Chicago, v. 71, n. 6, p. 492-495, 2006.

GONÇALVES, A. A.; EBERLE, I. R. Frozen yogurt com bactérias probióticas. Alimentos e Nutrição, Araraquara, v. 19, n. 3, p. 291-297, 2008.

GUINARD, J. X.; LITTLE, C.; MARTY, C.; PALCHAK T. R. Effect of sugar and acid on the acceptability of frozen yogurt to a student population. Journal of Dairy Science, Champaign, v. 77, n. 5, p. 1232-1238, 1994.

GUNER, A.; ARDIC, M.; KELES, A.; DOGRUER, Y. Production of yogurt ice cream at different acidity. International Journal of Food Science and Technology, Oxford, v. 42, n. 8, p. 948-952, 2007.

GÜVEN, M.; KARACA, O. B. The effects of varying sugar content and fruit concentration on the physical properties of vanilla and fruit ice cream-type frozen yogurts. International Journal of Dairy Technology, Huntingdon, v. 55, n. 1, p. 27-31, 2002.

HEKMAT, S.; McMAHON, D. J. Survival of Lactobacillus acidophilus and Bifidobacterium bifidum in ice cream for use as probiotic food. Journal of Dairy Science, Champaign, v. 75, n. 6, p. 1415-1422, 1992.

INSTITUTO ADOLFO LUTZ - IAL. Métodos fisicoquímicos para análise de alimentos. 4. ed. São Paulo: IAL, 2008. $1020 \mathrm{p}$.

KEMP, S. E.; HOLLOWOOD, T.; HORT, J. Sensory evaluation: a practical handbook. Oxford: WilleyBlackwell, 2009. 196 p.

KIM, S. H.; LIM, C. H.; LEE, C.; AN, G. Optimization of growth and storage conditions for lactic acid bacteria in yogurt and frozen yogurt. Journal of the Korean Society for Applied Biological Chemistry, Seoul, v. 52, n. 1, p. 76-79, 2009.

LOPEZ, M. C.; MEDINA, L. M.; JORDANO, R. Survival of lactic acid bateria in commercial frozen yogurt. Journal of Food Science, Chicago, v. 63, n. 4, p. 706-708, 1998. 
MARSHALL, R. T.; GOFF, H. D.; HARTEL, R. W. Ice cream. 6. ed. New York: Aspen Publishers. 2003. 366 p.

MEILGAARD, M.; CIVILlE, G. V.; CARR, B. T. Sensory evaluation techniques. 4. ed. Boca Raton: CRC, 2007. $448 \mathrm{p}$.

ORDONEZ, G. A.; JEON, I. J.; ROBERTS, H. A. Manufacture of frozen yogurt with ultrafiltered milk and probiotic lactic acid bacteria. Journal of Food Processing and Preservation, Westport, v. 24, n. 2, p. 163-176, 2000.

R DEVELOPMENT CORE TEAM. $R$ : a language and environment for statistical computing. Vienna: $\mathrm{R}$ Foundation for Statistical Computing, 2007.

RODAS, M.A.B.; RODRIGUES, R. M. M. S.; SAKUMA, H.; TAVARES, L. Z.; SGARBI, C. R.; LOPES, W. C. C. Caracterização físico-química, histológica e viabilidade de bactérias lácticas em iogurtes com frutas. Ciência e Tecnologia de Alimentos, Campinas, v. 21, n. 3, p. 304309, 2001.

RODRIGUES, M. V. N.; RODRIGUES, R.A. F.; SERRA, G. E.; ANDRIETTA, S. R.; FRANCO, T. T. Produção de xarope de açúcar invertido obtido por hidrólise heterogênea, através de planejamento experimental. Ciência e Tecnologia de Alimentos, Campinas, v. 20, n. 1, p. 103-109, 2000.

SALVADOR, A.; FISZMAN, S. M.; CURIA, A.; HOUGH, G. Survival analysis applied to sensory shelf life of yogurts - II: Spanish formulations. Journal of Food Science, Chicago, v. 70, n. 7, p. 446-449, 2005.

SCHMIDT, K. A.; KIM, J.; JEON, I. K. Composition of carbohydrates and concentration of $\beta$ galactosidase of commercial frozen yogurt. Journal of Food Quality, Oxford, v. 20, n. 5, p. 349-358, 1997.

SOLER, M. P.; VEIGA, P. G. Sorvetes - série publicações técnicas do centro de informação em alimentos. Campinas: ITAL, 2001. 63 p.

SOUKOULIS, C.; TZIA, C. Impact of the acidification process, hydrocolloids and protein fortifiers on the physical and sensory properties of frozen yogurt. International Journal of Dairy Technology, Huntingdon, v. 61, n. 2, p. 170-177, 2008.

STONE, H.; SIDEL, J. L. Sensory evaluation practices. 3. ed. London: Elsevier Academic Press, 2004. 377 p.

TAMIME, A. Y.; ROBINSON, R. K. Yoghurt Science and technology. 3. ed. Boca Raton: CRC, 2007. 791 p.

TIESZEN, K. M.; BAER, R. J. Composition and microbiological quality of frozen yogurts. Cultured Dairy Products Journal, Washington, v. 24, n. 4, p.1314, 1989.

TRAMONTINA, T.; RICHARDS, N. S. P. S.; SILVA, M. E. Desenvolvimento e caracterização físico-química, microbiológica e sensorial de iogurte adicionado de cereais integrais. In: CONGRESSO NACIONAL DE LATICÍNIOS, 28., 2001, Juiz de Fora. Anais... Juiz de Fora, jul. 2001. p. 225-229.

VARGHESE, K. S.; MISHRA, H. N. Modelling of acidification kinetics and textural properties in dahi (Indian yogurt) made from buffalo milk using response surface methodology. International Journal of Dairy Technology, Huntingdon, v. 61, n. 3, p. 284-289, 2008. 